\title{
Veinte años desde la caída del muro de Berlín
}

\author{
Ignacio SoTELO \\ Berlín
}

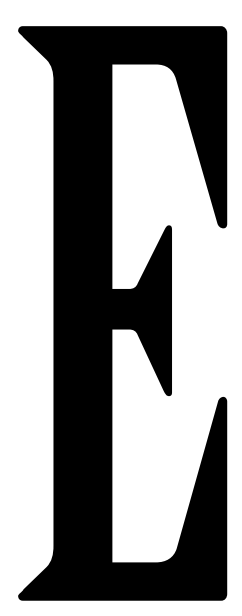

1 sábado 31 de octubre, ante 1800 invitados, entre los que se encontraban el presidente y la canciller de la República Federal de Alemania, la Fundación Konrad Adenauer conmemoró «la caída del muro y la reunificación». Como invitados especiales intervinieron tres protagonistas, George Bush senior, Michail Gorbachov y Helmut Kohl. Aunque la caída del muro fuese la condición previa a la unificación, es preciso distinguir ambos acontecimientos que tuvieron dinámicas muy distintas.

\section{La construcción del Muro}

Pero antes de preguntarse por las causas que llevaron a la caída del muro es necesario recordar el porqué se levantó el 13 de agosto de 1961. Después de haber negado por activa y por pasiva que se tuviera la menor intención de cerrar la única frontera, la de Berlín, que permanecía abierta debido a la ocupación cuatripartita de la ciudad, de repente y por sorpresa en una noche se colocaron las alambradas, el Muro mismo tardó semanas en terminar de construirse. Una verdadera hazaña que llevó a cabo Erich Honecker, que luego sustituiría a Walter Ulbricht como secretario general del partido y Jefe de Estado. De haberlo sospechado la población, y no digo de haber sido advertidos, miles se hubieran precipitado a abandonar la RDA. Es lo que explica la construcción del Muro: mientras que los jóvenes mejor preparados escapasen a la República Federal al terminar los estudios, era imposible salir del estancamiento. La Unión Soviética no tuvo más remedio que apoyar una medida que desprestigiaba a todo el bloque comunista.

En aquellos días me encontraba cerca de Bonn, en un congreso mundial de estudiantes, representando a la FUDE, (las siglas me parece que eran de la Federación Universitaria Democrática

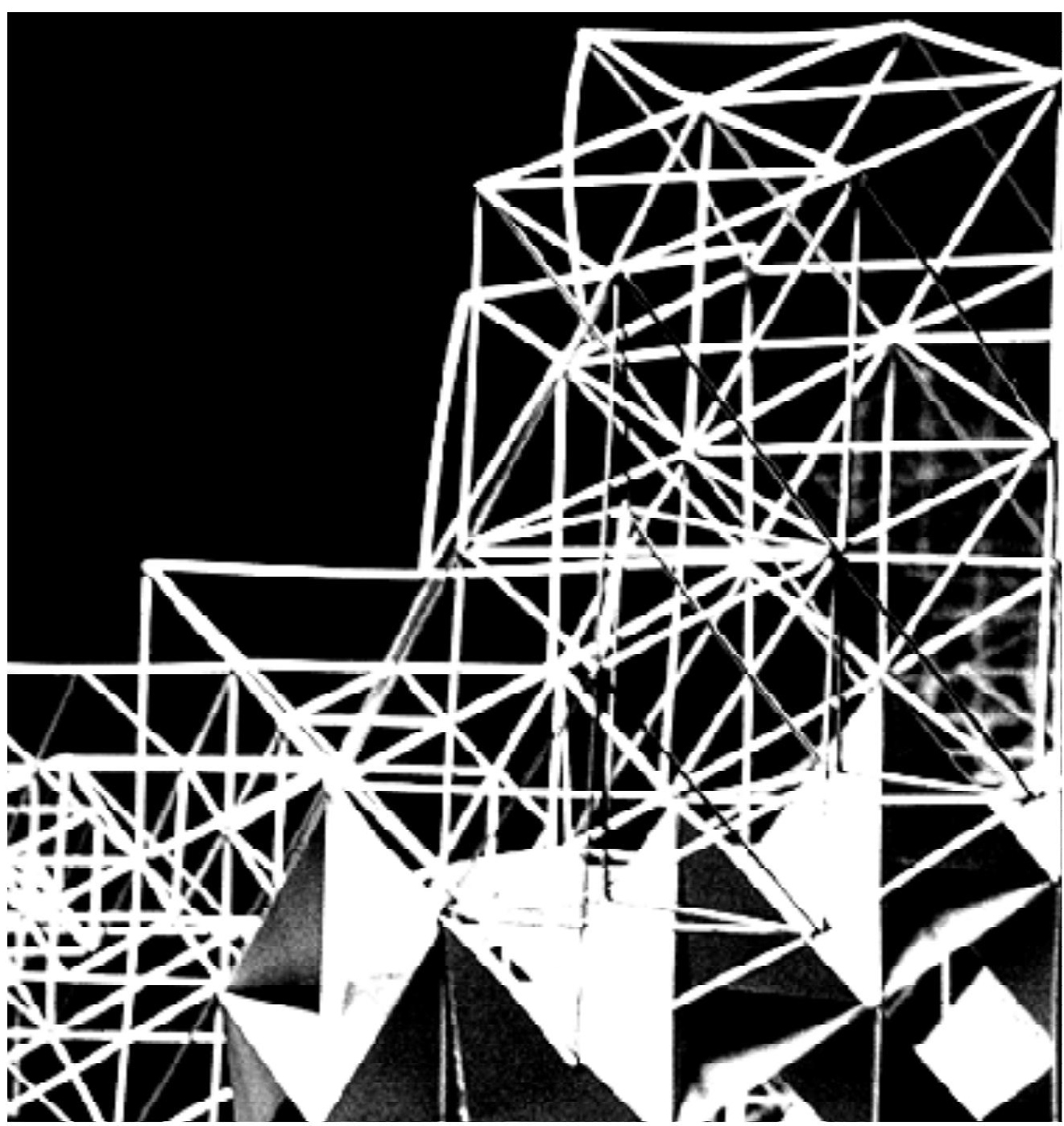

Española), cuando en la mañana del 13 de agosto recibimos una invitación del Gobierno Federal para trasladarnos a Berlín y ser testigos directos de lo que estaba ocurriendo. Se organizó una gran trifulca, porque la mayoría de los delegados de África y América Latina, de ideología revolucionaria, o infiltrados por los partidos comunistas, alegaban que aceptar la invitación suponía hacer el juego a la propaganda «imperialista» y que, por lo demás, los países socialistas tenían derecho a defenderse de los ataques del exterior. En este fuego cruzado de propagandas -en aquellos años de la "guerra fría» todo se veía con anteojos bur- 
damente ideológicos- fui de los pocos que aceptaron la invitación, convencido de que lo mejor para hacerse una opinión de lo que estaba pasando era observarlo directamente. Pocos meses antes había visitado la ciudad por primera vez y quedé impactado ante el contraste entre el Berlín oriental, que en el lenguaje ideológico de entonces se autodenominaba «democrático», y el Berlín occidental, llamado «libre».

A un lado y otro de la alambrada, se habían estacionado tanques soviéticos y norteamericanos, anunciando que podría estallar la tercera guerra mundial, que, sin embargo, parecía harto remota, al observar como los tanquistas rusos y americanos se hacían bromas y se tiraban caramelos. En cambio, en Berlín occidental -al oriental no pude pasar- la población estaba consternada. Por doquier grupos, más o menos grandes, de personas de todas las edades y orígenes sociales se lamentaban sobre el trágico destino que tendría la ciudad si los norteamericanos permitieran el cierre de la frontera sin reaccionar militarmente. Tucídides ya comentó en la guerra del Peloponeso que el mayor belicismo irresponsable proviene de las masas populares, propensas siempre a responder con la fuerza, sin tomar en consideración las consecuencias. Salí convencido de que, si bien cerrar la frontera rompía los acuerdos, era una señal clara de debilidad del bloque comunista y lo más desatinado hubiera sido tratar de impedirlo recurriendo a las armas. Por vías diplomáticas ya se encontrarian soluciones que no amenazasen el mantenimiento de la paz, sin duda el bien principal, pero sobre todo imprescindible en un mundo basado en la «disuasión por el terror».

Cerrar herméticamente la frontera, por mucho descrédito que comportase, parecía la única solución para avanzar en la construcción del socialismo. Se daba por descontado que una medida tan impopular desaparecería tan pronto como se hiciera patente la superioridad del sistema, y entonces el movimiento migratorio iría en sentido contrario, el proletariado explotado acudiría en masa al paraíso comunista. La propaganda del Este presentaba el Muro como una medida provisional de autoprotección, imprescindible mientras fuese manifiesta la inferioridad del bloque socialista, que la propaganda oficial atribuía a los ataques del exterior. Pero según pasaron los años y el nivel de vida occidental subía y el del este permanecía estancado, crecía en la población el afán de escapar. Cuánto más necesario se hacía el Muro para sostener el régimen, menos verosímiles parecían las explicaciones que se daban.

Para la Alemania federal, y en general para el mundo occidental, el Muro significó la confirmación en cemento del fracaso del comunismo. En la Europa occidental, no así en el mundo sub- desarrollado recién liberado del colonialismo, se hundió la esperanza de que cupiese construir un orden más justo y eficaz, tomando como modelo al soviético. Una parte creciente de la clase obrera se conformó con el orden socioeconómico establecido, sin que con un crecimiento continuo de los salarios y un Estado social en expansión hubiese mucho de qué quejarse. La construcción del Muro cambió las tornas, trasladando a occidente las expectativas de un mundo mejor.

Alemania occidental ganó la batalla ideológica, pero al precio de perder el aporte masivo de mano de obra cualificada que habla la misma lengua y tiene la misma cultura. El «milagro alemán» no se entiende sin los compatriotas obligados a abandonar los territorios del este y sin los huidos de la Alemania oriental. Para la Alemania Federal la consecuencia más grave de la construcción del Muro fue verse obligada a importar en grandes cantidades mano de obra extranjera. El que en una buena medida proviniera de Turquía fue debido a la presión directa de Estados Unidos, que pretendía con ello ayudar a su principal aliado en la frontera con la Unión Soviética. Ha sido una de las secuelas del Muro, todavía presente, pero de la que menos se habla.

\section{La caída del Muro}

28 años más tarde el cómo y el momento de la apertura del Muro sorprendió a todos, al resultar de una serie de circunstancias que se combinaron de forma tan fortuita como imprevisible, sin que nadie la planeara. El que hasta bien avanzado el año 1989 nadie contase con esta posibilidad lo confirma una anécdota. La Embajada de España en Berlín fue bombardeada poco despues de inaugurarse en 1943 y, excepto la parte reconstruida para consulado general, permaneció decenios abandonada. Según me contó Bernard Vogel, entonces Presidente de la Fundación Konrad Adenauer, en 1988 se empezó a negociar, y a principios de 1989 se estaba a punto de llegar a un acuerdo, por el que la Fundación reconstruiría el edificio y lo ocuparía durante 99 años, dejando espacio para el consulado y un instituto de cultura español. Ante la pregunta de un funcionario de exteriores de qué pasaría si se reunificasen los dos Estados alemanes y la capitalidad volviese a Berlín, la parte alemana manifestó que no habría inconveniente en devolver el edificio reconstruido para que sirviera de embajada de España. No se concluyó el acuerdo, las cosas de palacio van despacio, y a partir de la primavera de 1989 fueron los alemanes los que ya no estuvieron dispuestos a firmarlo.

El motor que puso en marcha todo el proceso fue sin la menor duda la política de «restructuración y transparencia» que 
inició Gorbachov para sacar a la Unión Soviética de la profunda crisis en que se debatía, que la presión armamentística de la América de Reagan potenciaba al máximo. Para poner en marcha, sin paños calientes, una reforma radical de todo el sistema había que empezar por desprenderse de la pesada carga que para la Unión Soviética representaban los Estados socialistas integrados en su órbita. La gran paradoja era que los países del Este percibiesen la integración económica en el COMECON como una dura imposición de la potencia hegemónica, a la vez que ésta la sentía como una carga cada vez más gravosa. Una restructuración profunda del sistema (perestroika) exigía empezar por detectar (glasnost) la dura realidad que la propanganda había ocultado desde el primer día.

Ahora bien, una operación que pusiese en evidencia los males del sistema para luego tratar de remediarlos, sólo podría tener éxito si cada país la realizaba por su cuenta y riesgo. En el verano de 1989 Gorbachov no dejó la menor duda de que la Unión Soviética no intervendría en las cuestiones internas de los aliados. Esto repercutió de forma muy distinta en cada uno de estos países, aunque la tónica general, como cabía esperar, era no llevar la transparencia al extremo de que pusiese en cuestión la nomenklatura en el poder. En la RDA, al tratarse de una parte de una nación dividida, las reformas que demandaba Gorbachov tenían que contar con un gran rechazo, ya que el menor cambio podría ser altamente desestabilizador. En el fondo, las autoridades sabían, como el resto del mundo, que el régimen únicamente podía sostenerse con el apoyo directo de la Unión Soviética; abandonado a su suerte no podía durar mucho.

Al embajador de España en Berlín Oriental, Alonso Álvarez de Toledo, se le ocurrió la brillante idea de invitar una vez al mes a un plato típico español -una fabada, unas lentejas o un cocido madrileño- a intelectuales de prestigio, acompañados siempre de los correspondientes comisarios políticos para evitar cualquier sospecha de conspiración. Recuerdo que en estas reuniones, a las que el embajador tuvo la amabilidad de invitarme, desde comienzos de 1989 iba en aumento la tensión entre las dos partes. Los intelectuales elogiaban las libertades que poco a poco se conquistaban en la Unión Soviética, mientras que los funcionarios permanecían con la boca sellada, al no poder manifestarse de acuerdo, pero tampoco dispuestos a romper el tabú de criticar a la Unión Soviética. Como la permanencia de una RDA sin el apoyo soviético parecía harto improbable y resultaba inconcebible que pudiera enfrentarse a la potencia protectora, ni siquiera que pudiera negarse a seguir fielmente sus pasos, me hundí en un mar de dudas.

Las esperanzas de renovación que despertaba la política de Gorbachov, junto con el empeño de Honecker de impedir cualquier movimiento de renovación, trajeron consigo el que la población que se sentía protegida, incluso animada por la Unión Soviética, se distanciara cada vez más del partido y del aparato estatal. La ruptura llegó a la cima justo el 7 de octubre cuando en el Palacio de la República se celebraba el baquete oficial del 40 aniversario de la fundación de la RDA, con la asistencia de Gorbachov y todos los jefes de Estado de los países del bloque oriental, autoridades de la RDA y el cuerpo diplomático. Antes de que una manifestación de apoyo a Gorbachov, al grito de «Gorby, Gorby», que se han vuelto a escuchar en el vigésimo aniversario, pudiese rodear el edificio, los servicios soviéticos de seguridad decidieron sacarle de la sala. Tampoco los servicios de los otros Jefes de Estado iban a tolerar el menor riesgo, así que uno tras otro fueron abandonando el edificio, quedando sólo las autoridades germano-orientales y el cuerpo diplomático al empezar la comida. El 18 de octubre se obligó a Honecker a dimitir, cohete de salida para el rápido ocaso de la RDA.

El Muro cae por la política de Gorbachov, que abre la perspectiva de un socialismo distinto y la puerta a los que quieran escapar. En los primeros siete meses de 1989 se autorizó a 48.000 personas a abandonar Alemania Oriental y 9.000 lo consiguieron de manera ilegal. Estas concesiones no hicieron más que aumentar el número de los que querían salir, refugiádose cientos en las embajadas germano occidentales de Varsovia, Praga y Budapest, hasta que en el verano no hubo más remedio que abrir la frontera entre Hungría y Austria.

Una población cada vez más segura de que la Unión Soviética impediría una brutal re presión se atreve a sacar a la calle el malestar acumulado durante decenios. Cada vez más numerosas, las manifestaciones se expandían por todo el país. El 9 de octubre se manifestaron 70.000 personas en Leipzig, el 4 de noviembre ya fueron medio millón en Berlín oriental. La nueva dirección del partido no tenía otra opción que tirar lastre, abriendo vías de escape a la presión acumulada en tanto años, permitiendo salir a los que quisieran abandonar el país. La incapacidad del nuevo Jefe de Estado, Egon Krenz, y de la gerontocracia en el poder, quedó de manifiesto cuando se les escapó de las manos la decisión más importante que tenían que tomar: en qué condiciones y cuándo había que dejar salir a los que quisieran abandonar la República. Aquella noche del 9 de noviembre miles aprovecharon el desconcierto total en la cúspide para vivir la emoción de conocer el mundo del otro lado del Muro. Realmente el Muro cayó cuando, después de recorrer el centro de Berlín occidental, agotados, volvieron normalmente a dormir a casa, despidiéndose con un hasta mañana, convencidos de que ya nadie lo cerraría.

La caida del Muro es la consecuencia de dos políticas opuestas, la de las reformas y la de impedir cualquier modificación por muy insostenible que fuese la situación. Gorbachov y Honecker fueron, el uno sin quererlo directamente y el otro oponiéndose por completo, los artífices de la caída del Muro. El comunismo soviético se desmorona, justo cuando para remozarse trata de desprenderse de los países del este a los que explota y, sin embargo, lo vive como una carga. La crisis del comunismo tendría más que ver con la construcción del Muro que con su derrumbe. Su caída no arrastra consigo al comunismo, sino que es el intento de reformarlo lo que lleva a que se desmorone, cuando el régimen se hallaba en las últimas, aunque sorprendentemente pocos dentro y fuera de la Unión Soviética lo supieran. El reame acelerado al que obligó Reagan a la Unión Soviética no supuso más que la puntilla a un toro ya casi muerto.

En la gran crisis de los años treinta, el modelo soviético todavía re presentó una alternativa al capitalismo que atraía a millones. La rápida industrialización de la Unión Soviética pareció a muchos un gran éxito, muy digno de imitarse, no sólo por los países poco desarrollados, como España o Latinoamérica, sino incluso por los más avanzados que, como consecuencia de la cri- 
sis, sufrían un desempleo masivo. La ascensión del fascismo y del nacionalsocialismo no se entiende sin el desafío que significó la Unión Soviética de Stalin, cuyos logros se ensalzaban, a la vez que se ocultaban sus crímenes, incluso se disculpaban como daños colaterales necesarios para que la humanidad diera el gran salto. Hasta la construcción del Muro, el comunismo soviético fue la gran esperanza para una buena parte de la clase obrera y de los intelectuales de los países industrializados, pero sobre todo para la inmensa mayoría en los países más pobres.

La cuestión que se plantea es por qué se derrumbó el orden social que surgió con la Revolución de octubre. Los convencidos de que no existe alternativa viable al capitalismo, pensaron desde el primer día que un colectivismo estatalista planificado no podría durar mucho. Cae por su propio peso que se desplomara, sin necesitar explicación alguna. De lo único que, en todo caso, habría que dar cuenta es por qué un experimento que en teoría no podía funcionar ha durado 70 años. Para los que creemos que al capitalismo también le llegará su fin, -ahora sabemos que nuestra civilización, como todas las que la precedieron,

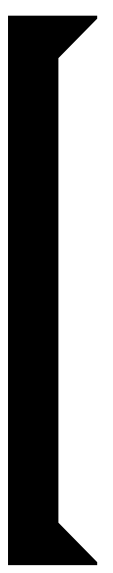

Gorbachor ha repetido estos días que a Estados

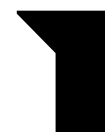

Unidos le toca esta vez llevar a cabo su peres-

troika, que tiene también en Obama su artífice,

ojalá sin las consecuencias demoledoras que tut

vo el intento en la Unión Soviética.

son mortales, como diría Paul Valéry- echamos de menos un análisis satisfactorio de lo ocurrido. No basta con afirmar, como hace una cierta izquierda, que hay que volver a intentarlo sin los errores y, espero, sin los crímenes del experimento anterior. Es menester identificar errores y crímenes para no reproducirlos, amparados en la certeza de que la historia no se repite tal cual. Es una tarea que no cabe rehuir en la actual crisis, que no es una más del ciclo, ni tan sólo del sistema capitalista, sino que cala mucho más hondo, como la crisis de nuestra civilización. Gorbachov ha repetido estos días que a Estados Unidos le toca esta vez llevar a cabo su perestroika, que tiene también en Obama su artífice, ojalá sin las consecuencias demoledoras que tuvo el intento en la Unión Soviética.

\section{La unificación}

Lo primero que hay que tener en cuenta es que la unificación también se produjo de manera muy diferente a la esperada, y ello marcó de manera decisiva los años venideros. Se esperaba que, recuperada la democracia en la Alemania Oriental, ambos Estados negociarían el camino de la unificación. A los 20 días de la caída del Muro, el canciller Kohl presentó un plan de diez puntos, en el que, pese a ser muy consciente del riesgo que corría en un contexto internacional marcado por la crisis interna de la Unión Soviética, daba por descontado que el proceso duraría varios años. La unificación llegaría, pero nadie sabía cómo ni cuándo.

El sueño de una minoría de izquierdas, que la unificación de los dos Estados alemanes en una Alemania nueva hubiese facilitado la fusión de lo mejor del capitalismo con lo mejor del socialismo, se hundió inmediatamente en un proceso acelerado de unificación. La ilusión de la mayoría de que el desplome del comunismo llevaría a la hegemonía definitiva de Estados Unidos con su modelo de economía libre y de democracia representativa, para cualquiera que conociese un poco el mundo en que vivimos no tenía otro destino que despeñarse también en la nada. Empero, muy pronto se esfumó el modelo de unificación que se había manejado durante decenios, como si hubiera sido sólo el sueño vano de la izquierda que apostaba por una «tercera vía». Tres factores cambiaron en pocas semanas la dirección del proceso: 1 . En cuanto se abrió la frontera, se inició un éxodo hacia occidente-medio millón de personas hasta las elecciones de marzo de 1990-, que se suponía que iría en rápido aumento, dada la dependencia económica de la RDA de un COMECON (19491991) a punto de desmoronarse. 2. La victoria de la democracia cristiana en las primeras y únicas elecciones libres de la RDA -en el fondo, las elecciones las ganó Kohl- mostró la voluntad mayoritaria de integrarse lo antes posible y sin condiciones en la República Federal. 3. A la renuencia de los aliados europeos a convivir en un futuro próximo con una Alemania unida -sobre todo el Reino Unido de Thatcher y la Francia de Mitterrandhay que añadir que Estados Unidos apoyaba el proceso únicamente si Alemania permanecía en la OTAN y en la Comunidad Eu ropea, dos condiciones a las que la Unión Soviética siempre se había opuesto.

La unificación fue posible en un tiempo récord, gracias a que Kohl negoció sólo con Gorbachov, llegando a un acuerdo por el que la Unión Soviética reconocía la soberanía plena de la Alemania unida para mantener las alianzas que considerase oportunas, y Alemania aceptaba las condiciones de la Unión Soviética, concernientes a la prohibición de armas nucleares, biológicas y químicas, y una reducción de los Ejércitos a un máximo de 370.000 soldados -los de los dos Estados sumaban 530.000- y corriese con los costos que ocasionase la salida de los 400.000 efectivos soviéticos de Alemania Oriental. Hubiera sido una buena idea haber otorgado en su momento el premio Nobel de la paz a Gorbachov y Kohl.

Desde el principio Alemania supo que la unificación iba a costar mucho, aunque luego el precio resultase muchísimo más alto de lo calculado. La primera consecuencia de la unificación fue económica. Aunque se ampliase el mercado interno, el enorme gasto público que la unificación trajo consigo ralentizó el crecimiento durante muchos años. A pesar de la crítica aniquiladora del nacionalismo que significó la derrota, el sentimiento de constituir una nación estaba lo bastante arraigado para que el altísimo gasto público no fuese un impedimento. Muy pocos se opusieron a la unificación por el gasto que se preveía, pero explica que la euforia en el oeste fuese mucho menor que en el este. Se- 
gún el periódico Berliner Morgenpost de 17 de septiembre de 2009 , en una encuesta hecha para el semanario Stem, el $16 \%$ de los alemanes occidentales y el $10 \%$ de los orientales quisieran que los dos Estados alemanes siguieran existiendo; incluso el $15 \%$ de la población desea que se vuelva a edificar el muro para mantener a cada uno en su sitio. Seguro que estas cifras serían mucho más altas si la encuesta se hiciera en alguno de los países vecinos.

Hay que recalcar, en segundo lugar, que la unificación se llevó a cabo, tratando de reducir a un mínimo las mudanzas en la vieja República Federal. Sí hubo disposición a pagar lo que fuese necesario, en cambio, no a modificar lo más mínimo las estructuras económicas, sociales, políticas existentes, aunque ello implicase forzar a la antigua RDA a encajar en el modelo occidental sin concesiones. Para ello fue necesario que la Alemania socialista empezase por autodisolverse, de modo que cada uno de los Estados Federados resultantes pudiera ser anexionado sin que la estructura política, social y económica de la República Federal cambiase lo más mínimo. En vez de una negociación entre los dos Estados para configurar uno nuevo, se recurrió al artículo 23 de la Ley Fundamental de Bonn que permitía anexionar cada uno de los 5 Estados Federados en los que la república unitaria del este se había autodisuelto. Luego se suprimió este artículo para evitar la sospecha de que en el futuro el procedimiento pudiera repetirse en cualquier otro país germánico, como por ejemplo en Austria.

Se renunciaba con ello a la que había sido la más traída y llevada aspiración del pueblo alemán: recobrada la soberanía, darse por fin una constitución. A la Ley Fundamental vigente no se la considera tal, porque en su elaboración no participaron representantes de todo el pueblo alemán, ni los aliados occidentales pemitieron que fuese ratificada en referéndum. La Constitución alemana de facto carece de legitimidad en el sentido más estricto, pero soportar esta deficiencia era imprescindible para garantizar que nada cambiase.

\section{Las consecuencias de la caída del Muro}

Las consecuencias de la apertura del Muro sobrepasan con mucho Alemania, que consiguió la unificación. La Unión Soviética se desplomó, después de haber puesto punto final a la Guerra Fría en diciembre de 1989. Cesa el enfrentamiento de las dos ramas en las que se había dividido la clase obrera, por la triple consunción de la clase, el comunismo y la socialdemocracia. Es una falsa percepción creer que el declive de la socialdemocracia y el final del comunismo están de alguna forma ligados. Con la caída del Muro se habrían desplomado todos los socialismos y comunismos del pasado y del futuro. No se olvide que la socialdemocracia se congratuló de la caída del comunismo, su principal adversario. La historia le daba la razón, a la vez que sacaba del escenario al principal contrincante. El declive de la socialdemocracia ya había empezado 10 años antes de la caída del Muro con la irrupción del liberalismo radical de Reagan y Thatcher, que pusieron en cuestión su mayor logro, el Estado de Bienestar. El deterioro del movimiento obrero, la sinergia de sindicatos y partido socialdemócrata, había empezado a comienzos de los 80 . Tiene muy diversas causas, pero la principal es que en los últimos 20 años ha ido periclitando la base social de la socialdemo-

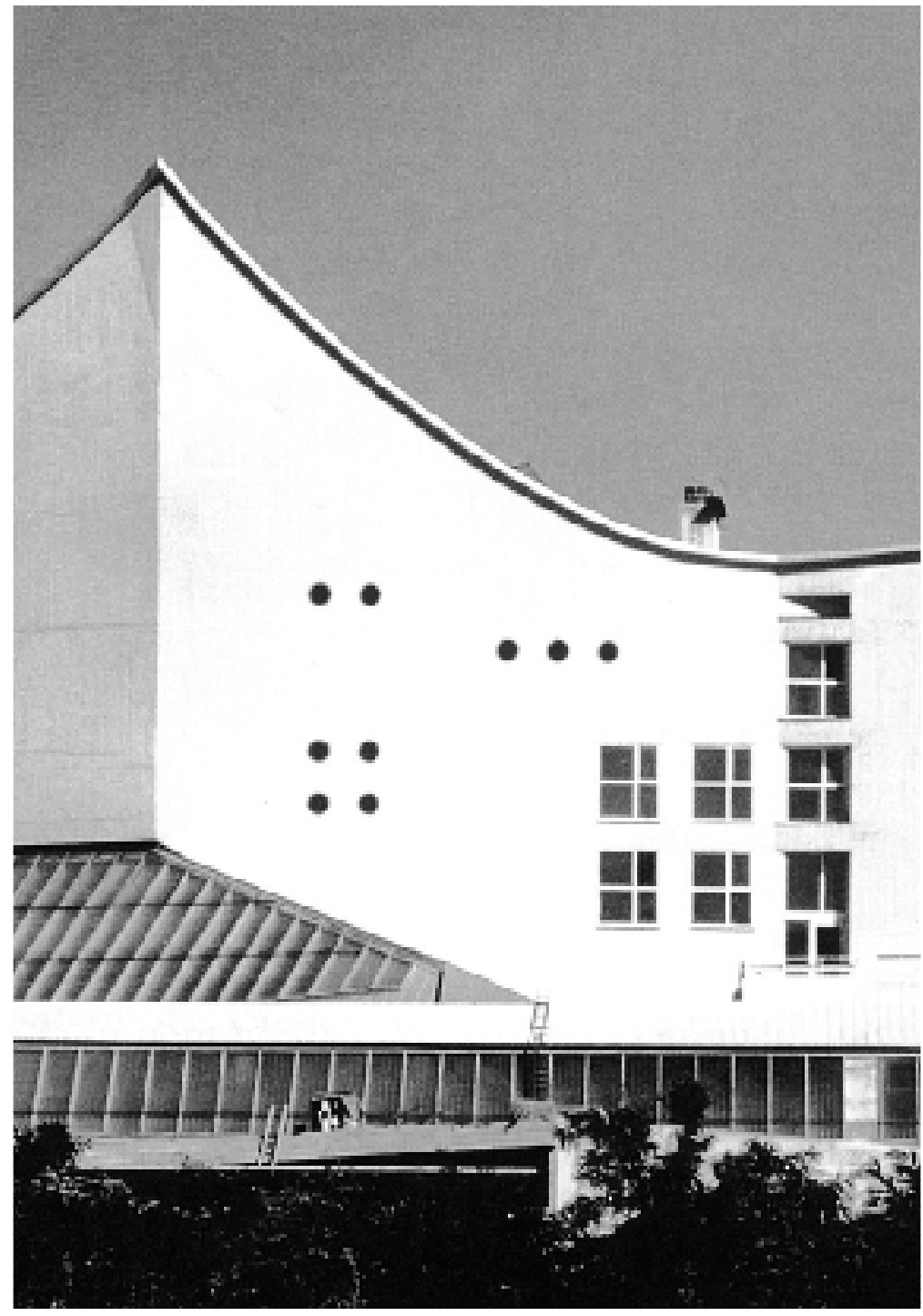

cracia: el trabajador con un puesto seguro y salario en ascenso es cada vez más rara avis.

En Europa se aceleró el proceso de integración, en el último momento para aceptar la unificación, Mitterrand impuso la adopción del euro; con una Alemania unida y soberana el marco alemán no podía seguir siendo la divisa líder. En fin, se volvió a la mundialización, ahora llamada globalización, tal como estaba en marcha antes de la Primera Guerra Mundial, al desaparecer el bloque comunista, el llamado «Segundo Mundo». En efecto, 1989/1990 cierra toda una época, no sólo en Alemania, sino en todo un mundo ya globalizado, en el que la historia empieza a ser de verdad universal.

La caída del Muro inaugura una nueva época histórica. En Alemania supuso que la »República de Bonn « se convirtiese en la que se ha dado en llamar "República de Berlín». Si existe un amplio consenso sobre las diferencias fundamentales entre Bonn y Weimar, debidas en primer lugar a las que distinguen la segunda posguerra de la primera -una Alemania totalmente destruída y ocupada por los aliados- sin contar todas aquellas otras que provienen de tratar de evitar que pudiese repetirse el 
mismo destino. En cambio, la opinión pública alemana y, claro está, en mayor medida la extranjera, no tienen tan claro en qué, si en algo fundamental, se diferencia la nueva República Federal de Alemania de la que desapareció en 1990. En las páginas que siguen me ocuparé de algunos de los cambios políticos, sociales, culturales, que la unificación ha traído consigo.

En estos veinte años los cambios ocurridos han sido muchos y significativos. Limitados a los que considero de mayor alcance, hay que mencionar en primer lugar la catástrofe demográfica de los nuevos Estados Federados. La rápida unificación no evitó que la población menor de cincuenta años, mejor preparada, más mujeres que hombres, siguiese emigrando a la otra Alemania. A pesar de las cantidades ingentes gastadas en modernizar las infraestructuras, la emigración y una reducción a la mitad del que ya era el índice de natalidad más bajo del mundo, ha supuesto dos decenios más tarde una pérdida de casi tres millones de habitantes, de los dieciséis que tenía. El hundimiento forzado de la economía oriental ha vaciado algunas ciudades, hasta el punto de que no ha habido otro remedio que poner en mar-

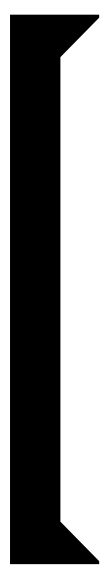

\section{Recuerdo que el entonces embajador de Argen-}

tina me decía: “Algunos llevamos la fama, pero el latrocinio en la privatización de la ex RDA supera con mucho lo que cabía esperar de una sociedad como la alemana”.

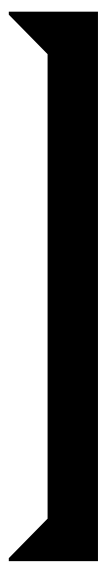

cha un programa para sufragar parte de los costos de demolición de más de un millón de viviendas desocupadas y sin posibilidad de que se ocupen. Una disminución tan drástica de la población no ha impedido, sin embargo, que los nuevos Estados den las cifras más altas de desempleo y, claro está, de población jubilada.

La unificación por la vía rápida empezó por cambiar un marco oriental supervalorado para alegría inmediata de la población del este, que veía salvados sus pequeños ahorros, pero con la consecuencia querida de desmantelar de un plumazo toda la economía de la antigua RDA. En un instante, una buena parte de la población quedó sin puesto de trabajo, pero la «economía de mercado» pronto los iría creando. Empero, enormes inversiones públicas no han servido para hacer realidad las falsas expectativas de entonces, y ello, porque en un mundo ya globalizado los nuevos Estados Federados han tenido que competir con una Alemania Occidental cuya capacidad productiva basta para abastecer a las dos partes y estar además entre los primeros exportadores del mundo.

El 17 de junio de 1990, todavía en la RDA, se creó una ins- titución estatal (Treuhandanstalt) encargada de privatizar las empresas y propiedades estatales que, considerablemente ampliada después de la unificación, pasó a depender del Ministerio de Hacienda. Las empresas fueron vendidas en su mayor parte a empresas alemanas -se justificó diciendo que había que evitar que cayesen en manos extranjeras, principalmente japonesas- pero los nuevos propietarios se apresuraron a cerrarlas, para evitar que un día pudieran competir con las occidentales, o simplemente para especular con el suelo o los edificios. Los muchos procesos de fraude y estafa que han emergido en estos años -seguro la punta del iceberg- confirman la que ha sido experiencia universal, la privatización de los bienes públicos constituye el mayor negocio para los amigos de los gobernantes, pero cuando lo que está en venta es un país entero, la corrupción sobrepasa con mucho los contactos personales. Recuerdo que el entonces embajador de Argentina me decía: «Algunos llevamos la fama, pero el latrocinio en la privatización supera con mucho lo que cabía esperar de una sociedad como la alemana».

La moral pública y la moral empresarial se amodorran en un proceso de privatización que en el tiempo coincide con la transformación vivida a partir de los 80 del capitalismo productivo en uno especulativo. Haber contribuído, en ningún caso fue la causa principal, a la desaparición de los antiguos valores que infundieron un día al capitalismo, es otra consecuencia de la unificación de la que menos se habla, pero probablemente de gran calado.

En suma, si se quiere recapitular en unas pocas palabras los últimos veinte años de la Alemania unida, habrá que empezar por ratificar la obviedad de que nada se entiende sin los veinte años anteriores. Se enfrentaban dos Berlines, dos Alemanias, con un desarrollo social, económico y político divergente, pero que no dejaban de tener algunos rasgos comunes, como el que por servir de escaparate del régimen respectivo ambos Berlines estuvieran fuertemente subvencionados. Al quedar aislado en una isla insegura, Berlín occidental había contemplado impotente como las grandes empresas se trasladaban a Alemania occidental. Perotambién en Berlín oriental la política de unificación destruyó de un plumazo toda su economía productiva. Berlín ha recuperado la capitalidad, Gobierno, Parlamento, la mayor parte de los Ministerios, que representa una fuente importante de ingresos, Berlín sin la capitalidad sería inviable. En el Berlín de hoy se concentra la investigación científica y la enseñanza superior, a la vez que se está consolidando como uno de los grandes cent ros culturales de Europa, abierto como Viena, a la del este. Desde la perspectiva de la sociedad del conocimiento, Berlín sigue buscando su perfil económico, como lo sigue buscando la Alemania Oriental. Berlín, todo Berlín pertenece a la Alemania Oriental con los problemas que la caracteriza.

Las diferencias entre las dos Alemanias siguen siendo considerables, sin que hasta hora en la oriental haya disminuido el paro o se haya igualado el nivel de vida de la población a la media de la Alemania occidental. Pero ambas partes ya eran diferentes antes de la Segunda Guerra Mundial. Como es distinta la Italia del norte de la del sur, así continuarán diferenciándose por mucho tiempo la Alemania Occidental de la Oriental. 